\title{
@OPENACCESS THE INFLUENCE OF MEDIA ON PERCEPTION OF BODY IMAGE IN MEDICAL STUDENTS OF PESHAWAR, PAKISTAN
}

\author{
Muhammad Ali', Mifrah Rauf Sethi², Muhammad Irfanæ2
}

${ }^{1}$ Student, Peshawar Medical College, Riphah International University, Islamabad-Pakistan

2 Department of Mental Health, Psychiatry and Behavioral Sciences, Peshawar Medical College, Riphah International University, Islamabad-Pakistan.

Address for correspondence: Muhammad Irfan

Department of Mental Health, Psychiatry and Behavioral Sciences, Peshawar Medical College, Riphah International University, Islamabad-Pakistan.

E-mail:

mirfan78@yahoo.com

Date Received:

January, $1^{\text {st }} 2021$

Date Revised:

July, $20^{\text {th }} 2021$

Date Accepted:

July, $20^{\text {th }} 2021$

This article may be cited as Ali M, Sethi MR, Irfan M. The influence of media on perception of body image in medical students of Peshawar, Pakistan. J Postgrad Med Inst 2021;35(2):75-9. https://doi.org/10.54079/ jpmi.35.2.2463.

\section{ABSTRACT}

Objective: To find out the effect of media influence on perception of body image and eating attitude in students of medical and dental institutes of Peshawar-Pakistan.

Methodology: A cross-sectional survey was conducted at medical and dental institutes of Peshawar, Pakistan from January to March 2019. All students from 1st year to final year were invited to complete Body Image States Scale (BISS), Eating Attitude Test (EAT-26) and Socio-cultural Attitudes Towards Appearance Questionnaire (SATAQ-3), along with providing demographic data on a semi structured proforma. The data was analyzed using SPSS-25, with Chi-square test and Pearson correlation test used as tests of significance.

Results: The mean age of the sample ( $n=908)$ was $20.84+1.7$ years. There were $529(58.3 \%)$ females, most of the sample was collected from Private sector $(n=841,92.6 \%)$ and from first year $(n=289,31.8 \%)$. The Cronbach's Alpha Reliability of BISS in our study was $0.866,0.834$ for EAT-26 and 0.888 for SATAQ-3. According to the responses, there were $430(47.4 \%)$ students having issues of body image, 387 (42.6\%) had problems with eating attitude and $502(53.3 \%)$ students were more influenced by the media. The Pearson correlation showed that body image, media influence and eating attitude are significantly positive correlated with one another at $p$ value of $<0.01$.

Conclusion: There is influence of media both on body image and eating attitude. The results of cronbach's alpha reliability of all the scales used in this study suggest that these scales can reliably be used in our setup.

Key Words: Medical students; Body image; Media influence; Eating disorder

\section{INTRODUCTION}

An eating pattern represents the summation of what individuals habitually eat and drink, and these dietary components act synchronously, in relation to health. Adolescence is a transition period during which individuals gradually take over the responsibility for their own eating habits. The physical, cognitive, social, and lifestyle changes during adolescence create profound changes in their eating patterns. Adolescents frequently develop eating disorders and have major public health impact. ${ }^{1}$

The nutrition in adolescence predicts the nutritional status of adults and can be used effectively to prevent the risk factors for diet-related non-communicable diseases. ${ }^{2}$ Improving self-esteem, body image and empowerment of eating attitudes can be an important solution towards early diagnosis and primary prevention of eating disorders. ${ }^{3}$ It is important to consider that the construct of body image is multidimensional. It includes cognitive, affective, behavioral and evaluative aspects of physical appearance. ${ }^{4,5}$ The evaluative body image changes with life experiences as an individual determines their own physical self-satisfaction and contextualizes sociocultural body ideals. ${ }^{4,5}$

Considering these, the body shape has been of particular area of interest for researchers around the globe. ${ }^{6,7}$ However, only few studies have examined the relationship of body shape with the role of media and other variables. ${ }^{5,711}$ Unfortunately, this connection has not been explored in our part of the world. Therefore, this study was planned to find out the effect of media influence on body shape and eating attitude among medical and dental students of Peshawar.

\section{METHODOLOGY}

A cross-sectional survey was conducted at medical and dental college of Peshawar-Pakistan from January to March 2019. Convenient sampling technique was be used. All the students from 1st to final year, consenting to participate were invited to fill the questionnaires. The 
study was approved by the ethical review committee of Prime Foundation Pakistan. The participation was entirely voluntary. Informed consent was taken from all the participants. Those consenting were requested to provide their demographic information on a semi structured proforma and respond to Body Image States Scale (BISS), Eating Attitude Test (EAT-26) and Socio-cultural Attitudes towards Appearance Questionnaire (SATAQ-3).

Body image Questionnaire (BISS) ${ }^{11}$ was used to measure individuals' evaluation about their body shape. It is a six-item measure of individuals' evaluation and affect about their physical appearance at a particular moment in time. The BISS is acceptably internally consistent.

Eating Attitude Test (EAT-26) ${ }^{12}$ was used for the assessment of individual's attitude towards eating. It is composed of 26 items. The scale is comprised of a combination of Likert ratings, dichotomous scores, behavioural frequency scores, and open-ended questions asking for weight and height.

Socio-cultural Attitudes Towards Appearance Questionnaire (SATAQ-3) ${ }^{13}$ was used to measuring media influence on an individual. It consists of 30 items with four subscales; few items have reverse scoring in order to remove biasness. Higher score indicates more media influence.

The inter-scale correlation of all the scales is given in Table No. 1-3.

Data was analyzed by using SPSS v.25. Analysis of the basic variables was carried out using descriptive statistics for finding frequencies and percentages. Cronbach alpha reliability was used to find out the reliability of the scales. Chi-square test was used to find out the differences based on gender, institutions, colleges and year of education on each scale. Pearson Correlation coefficient was used on BISS, EAT-26, SATAQ-3 to find out the inter-scale correlation. The results of all the test of significance were considered significant at $p<0.05$ level.

\section{RESULTS}

The mean age of the sample $(n=908)$ was $20.84+1.7$ years. There were 529 $(58.3 \%)$ females and most of the sample was collected from Private sector $(n=841$, $92.6 \%$ ) and from first year ( $n=289,31.8 \%$ ). The Cronbach's Alpha Reliability of BISS in our study was $0.866,0.834$ for EAT-26 and 0.888 for SATAQ-3. According to the responses, there were $430(47.4 \%)$ students having issues of body image, 387 (42.6\%) had problems with eating attitude and 502 $(53.3 \%)$ students were more influenced by the media. The details are given in table 4 .

Taking the ones with problems, there was insignificant gender wise correlation with

Table 1: Inter-scale correlation of Body Image States Scale

\begin{tabular}{|c|c|c|c|c|c|c|c|}
\hline S. No & Variables & I $\rho$ (P-Value) & II $\rho$ (P-Value) & III $\rho$ (P-Value) & IV $\rho$ (P-Value) & V $\rho$ (P-Value) & VI $\rho$ (P-Value) \\
\hline I & Physical appearance & 1 & & & & & \\
\hline II & Body size & $-.336^{\star \star}(0.000)$ & 1 & & & & \\
\hline IV & Physical attractiveness & $.062^{\star \star}(0.000)$ & $-.303^{\star \star}(0.000)$ & $-.180^{\star \star}(0.000)$ & 1 & & \\
\hline V & Looks & $.193^{\star \star}(0.000)$ & $-.086(0.010)$ & $-.407^{\star \star}(0.000)$ & $.156^{\star \star}(0.000)$ & 1 & \\
\hline
\end{tabular}

Table 2: Inter-scale correlation of Eating Attitude Test

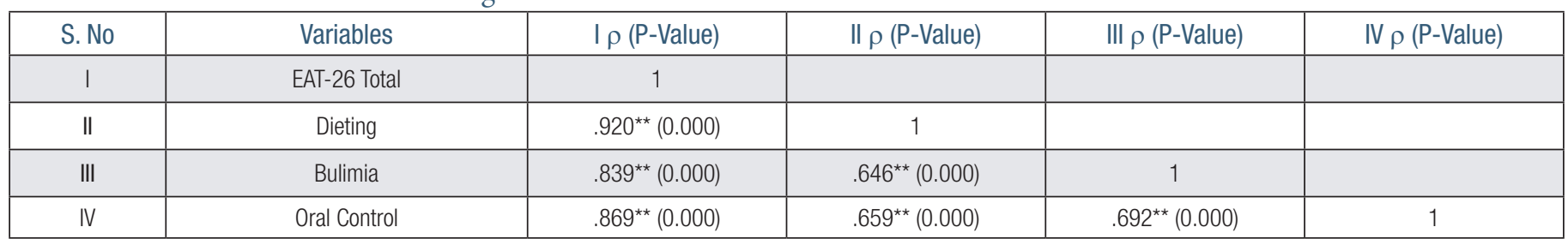

Table 3: Inter-scale correlation of Socio-cultural Attitudes Towards Appearance Questionnaire

\begin{tabular}{|c|c|c|c|c|c|c|}
\hline S. No & Variables & I $\rho$ (P-Value) & II $\rho$ (P-Value) & III $\rho$ (P-Value) & IV $\rho$ (P-Value) & V $\rho$ (P-Value) \\
\hline I & SATAQ-3 Total & 1 & & & & \\
\hline$\|$ & Information & $.804^{\star \star}(0.000)$ & 1 & & & \\
\hline IV & Internalization Gen & $.899^{\star \star}(0.000)$ & $.572^{\star \star}(0.000)$ & $.707^{\star \star}(0.000)$ & 1 & \\
\hline V & Internalization Ath & $.683^{\star \star}(0.000)$ & $.469^{\star \star}(0.000)$ & $.398^{\star \star}(0.000)$ & $.506^{\star \star}(0.000)$ & 1 \\
\hline
\end{tabular}


Table 4: Basic demographic details of the study ( $\mathrm{n}=908)$

\begin{tabular}{|c|c|c|c|}
\hline S. No & \multicolumn{2}{|c|}{ Variables } & Frequencies (\%) \\
\hline \multirow{2}{*}{1} & \multirow{2}{*}{ Gender } & Male & $379(41.7 \%)$ \\
\hline & & Female & $529(58.3 \%)$ \\
\hline \multirow{2}{*}{2} & \multirow{2}{*}{ Institutes } & Private & $841(92.6 \%)$ \\
\hline & & Public & $67(7.4 \%)$ \\
\hline \multirow{5}{*}{3} & \multirow{5}{*}{ Year of Education } & 1st year & $289(31.8 \%)$ \\
\hline & & 2nd year & $216(23.8 \%)$ \\
\hline & & 3rd year & $189(20.8 \%)$ \\
\hline & & 4th year & $124(13.4 \%)$ \\
\hline & & 5th year & $90(9.9 \%)$ \\
\hline \multirow{2}{*}{4} & \multirow{2}{*}{ BISS } & Low level of body image satisfaction & $430(47.4 \%)$ \\
\hline & & High level of body image satisfaction & 478 (52.6\%) \\
\hline \multirow{2}{*}{5} & \multirow{2}{*}{ EAT-26 } & No problem in eating attitude & $521(57.4 \%)$ \\
\hline & & Problems in eating attitude & $387(42.6 \%)$ \\
\hline \multirow{2}{*}{6} & \multirow{2}{*}{ SATAQ-3 } & Less media influenced & $406(44.7 \%)$ \\
\hline & & More media influenced & $502(55.3 \%)$ \\
\hline
\end{tabular}

Table 5: Gender wise distribution of BISS, EAT-26 and SATAQ-3 using chi-square test

\begin{tabular}{|c|c|c|c|c|}
\hline S. No & Variables & Male & Female & Chi-square value $(\mathrm{p}$-value $)$ \\
\hline 1 & BISS $(\mathrm{n}=430)$ & $177(41.1 \%)$ & $253(58.9 \%)$ & $.112(.738)$ \\
\hline 2 & EAT-26 $(\mathrm{n}=387)$ & $147(38.0 \%)$ & $240(62.0 \%)$ & $3.91(.048)$ \\
\hline 3 & SATAQ-3 $(\mathrm{n}=502)$ & $237(47.2 \%)$ & $265(52.8 \%)$ & $13.81(.000)$ \\
\hline
\end{tabular}

Table 6: Pearson correlation among BISS, EAT-26 and SATAQ-3. ( $\mathrm{n}=908)$

\begin{tabular}{|c|c|c|c|c|}
\hline S. No & Variables & I $\rho$ (P-Value $)$ & II $\rho$ (P-Value $)$ & III $\rho$ (P-Value $)$ \\
\hline I & BISS & 1 & & \\
\hline$\|$ & EAT-26 & $-.208^{\star \star}(0.000)$ & 1 & \\
\hline III & SATAQ-3 & $0.89^{\star \star}(0.000)$ & $-.143^{\star \star}(0.000)$ & 1 \\
\hline
\end{tabular}

BISS $(p=.738)$. However female students on EAT-26 and SATAQ-3 showed significant difference than male students $(p=.048$ and .000 respectively). Further details are given in table 5.

The Pearson correlation showed that body image, media influence and eating attitude are significantly positively correlated with one another at $p$ value of $<0.01$. Complete details are given in table 6 .

\section{DISCUSSION}

The purpose of this study was to find out the effect of media influence on body image and eating attitude in medical students of Peshawar. The age group to which our par- ticipants belonged should be seen in the context that at the beginning of the adolescence, concern over body image is expected to start which stays during the whole adolescence and diminishes thereafter. Our findings suggested that more female students were having low body image satisfaction when compared to their male counterparts on BISS, is in accordance with other studies. ${ }^{14-17}$

Also, our research findings are in accordance with other studies that suggest females to have more issues with eating attitude and at a higher risk of disordered eating ${ }^{18-20}$ but this is contrary to the findings of O'Reilly who found no difference between males and females in negative eating habits. $^{14}$
Our findings that media influenced the females more than the males, regarding their body image, is supported by McCabe et al ${ }^{21}$, Vivek et al ${ }^{22}$ and Uchôa et al. ${ }^{23}$ They suggested that the adolescents that internalize the ideals imposed by society as desirable are influenced by media which increases the chances of having issues with their body image. However, the findings of Buneto et al were in contrast with the results of our study. ${ }^{24}$

Our results are consistent with other studies that suggested that people with lower score on body image satisfaction will have higher levels of disordered eating. Thus it can be assumed that people with higher score in body image satisfaction, would score high in 
positive eating habits. ${ }^{14,25}$

Body image, media influence and eating attitude are correlated, as per the results of our study, which is supported by other studies. ${ }^{14,26,27}$ O'Reilly found body image satisfaction to be influenced by social media usage and suggested that "body image satisfaction and positive and negative eating habits predict social media usage". ${ }^{14}$ Holland et al and Li et al suggested a correlation between eating concerns and social media usage, and found that undergraduates who read online profiles of successful peers, have high levels of restrictive eating. ${ }^{26,27}$

\section{CONCLUSION}

Media influences the satisfaction with body image of an individual as well as altering the eating attitude. Since there is a high Cronbach's alpha score of all the scales used in this study, therefore all of these can reliably be used in our setup.

\section{REFERENCES}

1. Piran N, Levine MP, Steiner-Adair C. Preventing eating disorders: a handbook of interventions and special challenges. Philadelphia: Brunner/Mazel. 1999.

2. Hu P, Huang W, Bai R, Zhang F, Sharma M, Shi Z, et al. Knowledge, Attitude, and Behaviors Related to Eating Out among University Students in China. Int J Environ Res Public Health. 2016; 13(7): 696.

3. Yirga B, Gelaw YA, Derso T, Wassie MM. Disordered eating attitude and associated factors among high school adolescents aged 12-19 years in Addis Ababa, Ethiopia: a cross-sectional study. BMC Res Notes. 2016; 9: 503.

4. Smolak L. Body image in children and adolescents: where do we go from here? Body Image. 2004; 1:15-28.

5. Ferrer-García M, Gutie'rrez-Maldonado J. The use of virtual reality in the study, assessment, and treatment of body image in eating disorders and nonclinical samples: a review of the literature. Body Image. 2012;9(1):1-11.

6. Maxwell MA, Cole DA. Development and initial validation of the adolescent responses to body dissatisfaction measure. Psychol Assess. 2012; 24(3):721.

7. McCabe MP, Ricciardelli LA, Finemore $J$. The role of puberty, media and popularity with peers on strategies to increase weight, decrease weight and increase muscle tone among adolescent boys and girls. J Psychosom Res. 2002;52(3): 145-53.

8. Kenny U, O'Malley-Keighran M, Molcho M, Kelly C. Peer Influences on Adolescent Body Image: Friends or Foes? J Adol Res. 2017; 32(6):768-799.

9. Singh MM, Parsekar SS, Bhumika TV. Body image, eating disorders and role of media among Indian adolescents. $J$ Ind Assoc Child Adol Ment Health. 2016;12(1): 9-35.

10. Gondoli DM, Corning AF, Salafia EHB, Bucchianeri MM, Fitzsimmons EE. Heterosocial involvement, peer pressure for thinness, and body dissatisfaction among young adolescent girls. Body Image. 2011;8(2):143-8

11. Cash TF, Fleming EC, Alindogan J, Steadman L, Whitehead A. Beyond body image as a trait: The development and validation of the Body Image States Scale. Eat Disord. 2002(2); 10: 103-13.

12. Garner DM, Olmsted MP, Bohr Y, Garfinkel PE. The Eating Attitudes Test: psychometric features and clinical correlates. Psychol Med. 1982; 12(4):871-8.

13. Thompson JK, van den Berg P, Roehrig M, Guarda AS, Heinberg LJ. The sociocultural attitudes towards appearance scale-3 (SATAQ-3): development and validation. Int J Eat Disord. 2004; 35(3): 293-304.

14. O'Reilly I. Social media and its associations with body satisfaction, exercise and eating habits on undergraduate students. Thesis. 2018.

15. Tiggemann M, Williamson $S$. The effect of exercise on body satisfaction and self-esteem as a function of gender and age. Sex Rol. 2000; 43(1):119-27.

16. Prichard I, Tiggemann M. Objectification in fitness centers: Self-objectification, body dissatisfaction, and disordered eating in aerobic instructors and aerobic participants. Sex Rol. 2005; 53(1): 19-28.

17. Prichard I, Tiggemann M. Relations among exercise type, self- objectification, and body image in the fitness centre environment: The role of reasons for exercise. Psychol Sport Exerc. 2008; 9(6), 855-66.

18. Alireza FN, Hossein KH, Bahram PG, Alizadeh M, Rouzitalab T. Eating disorders risk and its relation to self-esteem and body image in Iranian university students of medical sciences. Eat Weight Disord. 2016; 21(4): 597-605. doi: 10.1007/s40519-016-0283-7.

19. Pritchard M. Disordered eating in undergraduates: Does gender role orientation influence men and women the same way. Sex Rol. 2008; 59(3): 282-9

20. Edman JL, Yates A, Aruguete MS, DeBord KA. Negative emotion and disordered eating among obese college students. Eati Behav. 2005; 6(4): 30817.

21. McCabe MP, Ricciardelli LA. A prospective study of pressures from parents, peers, and the media on extreme weight change behaviors among adolescent boys and girls. Behav Res Ther. 2005; 43(5): 653-68.

22. Shahi VK, Kohli N. Body image attitudes and perception among college students. IAHWA Int J Soc Sci. 2019; 7(5): 1263-7.

23. Uchôa FNM, Uchôa NM, Daniele TMC, Lustosa RP, Garrido ND, Deana NF, et al. Influence of the Mass Media and Body Dissatisfaction on the Risk in 
Adolescents of Developing Eating Disorders. Int J Environ Res Public Health. 2019; 16(9): 1508. doi: 10.3390/ ijerph16091508

24. Benuto L, Haboush A, Jones-Forrester S. Compensatory efforts for body dissatisfaction: Some gender and ethnic differences. New School Psychol Bull. 2007; 5(2):19-25.
25. Paxton SJ, Wertheim EH, Gibbons K, Szmukler Gl, Hillier L, Petrovich JL. Body image satisfaction, dieting beliefs, and weight loss behaviors in adolescent girls and boys. J Youth Adolesc. 1991; 20(3): 361-79.

26. Holland G, Tiggemann M. A systematic review of the impact of the use of social networking sites on body image and disordered eating outcomes. Body image. 2016; 17: 100-110

27. Li NP, Smith AR, Griskevicius V, Cason MJ, Bryan A. Intrasexual competition and eating restriction in heterosexual and homosexual individuals. Evol Hum Behav. 2010; 31(5): 365-72.

\section{Author's Contribution}

MA and MI conceived and conceptualized the idea and wrote the manuscript. MA also led data collection and data entry process. MRS did statistical analysis and helped in the write up of the study. MI critically revised the manuscript and supervised the study. Authors agree to be accountable for all aspects of the work in ensuring that questions related to the accuracy or integrity of any part of the work are appropriately investigated and resolved.

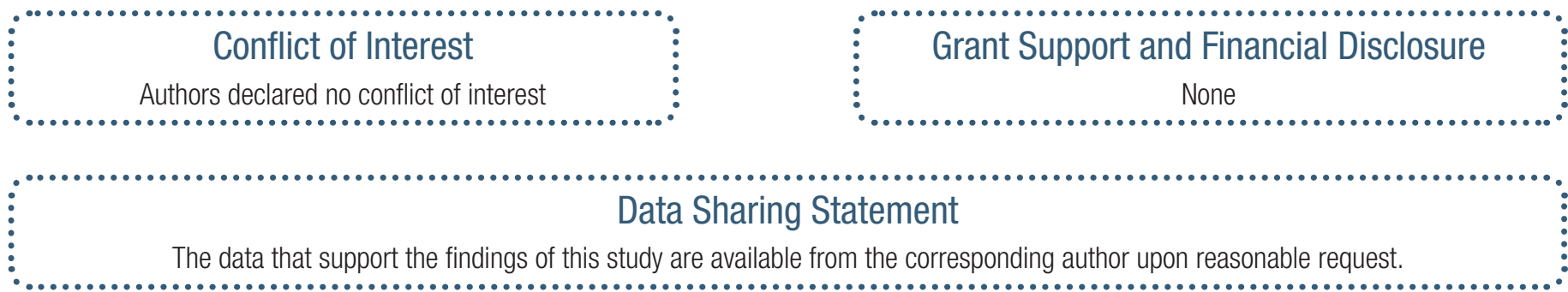

